\title{
An evaluation of the Fisher Hem-Alyzer
}

T. R. J. LAPPIN, A. LAMONT, AND M. G. NELSON

From the Department of Haematology, Royal Victoria Hospital, Belfast

SYNOPSIS The Fisher Hem-Alyzer is a multitest sequential discrete analyser with automatif printout of digitized results on paper tape. The instrument is well designed, soundly coos structed, and reliable in routine use. Cross contamination from the sampler probe or between the cuvettes is minimal. Accuracy and precision are both highly satisfactory. Although the standard rate of throughput is 32 specimens per hour the instrument can be used at irregula intervals to analyse smaller batches or even individual specimens. In a routine daily service the Hem-Alyzer was capable of handling a workload of 200 specimens per day, requiring three hours of laboratory technician time. The Hem-Alyzer produces only three parameters By not determining the packed cell volume it is not possible to incorporate the derived indice (MCV and MCHC) into the system and this, in the long term, is bound to be a disadvantage

For some time, we have conducted at this centre, a programme of evaluation of multichannel haematological equipment. The result of our experience with the Technicon SMA-4 has already been reported by Lappin, Lamont, and Nelson, and with the SMA-7A by Nelson (1969).

We have applied much the same methods of scientific evaluation to a study of the Fisher Hem-Alyzer. This equipment uses the principle of discrete sequential analysis to determine the haemoglobin concentration and the red and white cell counts. Approximately $1 \mathrm{ml}$ of mixed whole blood is placed in each sample cup, which is then inserted into one of the $\mathbf{4 8}$ numbered slots in the turntable head. Efficient mixing is achieved by a magnetic device located under the turntable which agitates each cup for a few minutes before it is presented in turn to the sampler probe. The Received for publication 22 October 1969. probe automatically removes $20 \mu \mathrm{l}$ of mixe whole blood, which is diluted with $5 \mathrm{ml}$ of isotonis saline in a cuvette. A further dilution is carrie out for the red cell count, requiring the remova of $20 \mu 1$ of the primary dilution, the transfer to $-a$ second cuvette, and the addition of a furthe $5 \mathrm{ml}$ of saline. Subsequently, the erythrocytes ate lysed when $40 \mu \mathrm{l}$ of a surface acting materig (Hemolyte, Fisher Limited) is injected into the first cuvette and aliquots of this haemolyse solution are used for the white cell and haem\& globin determinations. For aspiration and delivery of fluids the instrument uses high quali glass-barrelled syringes.

The diluted red and white cell suspensions a presented alternately to a flow cell by a reverse flow valve. The cells are counted by means of light scattering device, which monitors to flashes of light refracted from the cells in a dac 
field optical system. The haemoglobin is determined as oxyhaemoglobin by a split-beam dual photocell null balance filter photometer at $525 \mathrm{~nm}$ and the results are then read directly as $\mathrm{g} / 100 \mathrm{ml}$ of whole blood.

One and a half hours are required to complete the analysis of the 48 blood samples comprising the full turntable. Three minutes after sampling the results are presented in digital form printed on paper tape. Each set of results is identified by the number of the corresponding specimen position on the sample turntable and the nature of the analysis indicated by the letters ' $W$ ' for white cell count, ' $H$ ' for haemoglobin, and ' $R$ ' for red cell count.

The instrument measures $2 \mathrm{ft} 10$ in. by $1 \mathrm{ft} 9 \mathrm{in}$. by $1 \mathrm{ft} 4 \mathrm{in}$. in height, thus occupying approximately $6 \mathrm{sq} \mathrm{ft}$ of bench space. The accessory items, namely the printout and a sample mixer, each require approximately $1 \mathrm{sq}$ foot of bench space.

\section{Calibration}

Before the instrument was subjected to evaluation it was tested to see if the calibration of the three channels was correct. In order to test the accuracy of the haemoglobin and the red cell count channels, we used the red cell suspension which we routinely employ for standardization of our equipment (Nelson, 1969; Carville and Lee, 1969).

It was found to be a simple matter to calibrate the haemoglobin channel. After an initial warming-up period the galvanometer was zeroed by adjusting in turn the sample and reference screws and their respective lock nuts until the minimum reading was obtained. At this point the sample and reference sides of the colorimeter are in balance. The haemoglobin channel must then be calibrated for the day's run and for this purpose five aliquots of a sample of known concentration are placed in the first five sample cups of the turntable and the instrument is set in motion. When the first result appears on the printout the operator then adjusts the position of a small screw situated below the galvanometer to raise or lower the observed haemoglobin concentration to the required value. After the first adjustment the value of each successive result is visualized and final adjustments are made until the calibration of the haemoglobin channel is correct.

The instrument which was delivered to us gave results on the red cell count channel which were $1.5 \times 10^{6}$ per $\mathrm{c} \mathrm{mm}$ too high. This inaccuracy was present for samples of varying red cell concentration. It was found that recalibration of the red cell count channel was far from a simpie matter and could only be done by altering the volume of either the sample or diluent syringes. Neither of these was fitted with any reference point from which adjustment could readily be $\frac{c}{\varrho}$ made. As the diluent syringe was already set to $\overline{5}$ deliver its maximum possible volume, we had to $\square$ alter the sample syringe in order to make it $\frac{\mathscr{m}}{\vec{\sigma}}$ deliver a somewhat smaller volume. Although by this manoeuvre we were able to correct the red $\overrightarrow{\vec{F}}$ cell count there was a consequential fall in the $\stackrel{0}{?}$ observed white cell count. By making use of red ? and white cell characteristic curves at different $\frac{\bar{\sigma}}{\bar{D}}$ red cell threshold settings it was eventually $\frac{\vec{\sigma}}{\vec{\sigma}}$ possible to set the white cell count channel to $\varrho$ give the correct count value. This procedure was $\%$ tedious and time-consuming but once satisfactory $\overrightarrow{0}$ calibration had been achieved no resetting was found to be necessary. When this difficulty in $\vec{\omega}$ calibration was reported to the agents, they sub- $\frac{}{2}$ sequently evolved a step-by-step calibration? procedure, which in future will be incorporated $\underset{\omega}{N}$ in the operating instructional manual and they will undertake to make the calibration as part 8 of the initial installation.

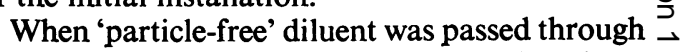
the instrument at high red cell threshold settings, T it was noted that a high particle count was 음 recorded. The presence of particles in an apparently particle-free fluid was related to the fil- $₹$ tration process, which was used in the preparation $\overrightarrow{0}$ of the diluent. Because a $0.45 \mu$ filter was used to prepare the diluent it is possible for particles of less than $0.45 \mu$ to be present in the fluid and at high threshold settings to be counted by the instrument. At the threshold settings used for blood cell counting, however, the presence of such $\frac{\mathrm{D}}{\mathbb{D}}$ small particles in the diluting fluid would not be counted.

Apart from calibration one other practical problem is the need to exclude the entry of air bubbles into the flow lines. This may occur through the reagent tubes or at the interface of the two sections of the reverse flow valve if this has not been properly sealed.

Also during operation it is important to see $\delta$ that the sample probe does not impinge on the rotating turntable. The cycle of movements may $ᄋ$ fall out of sequence due to operator error. The equipment should be protected from dust and reagents rendered free from contaminating particles greater than 0.5 microns.

Once the instrument had been properly cali- $N$ brated the subsequent evaluation followed a N predetermined schedule designed to determine 0 the carryover, the precision and accuracy, the mechanical and electronic stability, the maintenance and servicing requirements, the rate of $\stackrel{\oplus}{?}$ throughput, the problems of data handling, and the running costs.

\section{Carryover}

It is likely that the amount of carryover in the Fisher Hem-Alyzer will be largely determined by 흘 
contamination from the sample probe, which not only takes up the original aliquot of whole blood, but also removes a $20 \mu \mathrm{l}$ amount of diluted blood and transfers it from the first to the second mixing cuvette. In order to reduce cross-contamination the instrument has been so designed that the stainless steel needle probe is cleaned by passing it through a filter paper disc, both before and after each sampling or transfer manoeuvre. The actual degree of contamination was investigated using a radiosotope dilution method with radioiodinated albumin as a marker. The contamination was found to be less than $0.01 \%$ which is so minimal that it is unlikely to cause any significant carryover effect.

\section{Precision}

The precision was determined as previously described (Lappin, Lamont, and Nelson, 1969) by repeated analysis of the same blood sample and calculation of the standard deviation and coefficient of variation. Twenty replicate determinations were carried out on aliquots made from the same blood specimen (Table I).

The mean coefficients of variation obtained were $2 \cdot 18,1 \cdot 20$, and $1.88 \%$ for leucocyte count, haemoglobin concentration, and erythrocyte count respectively.

\begin{tabular}{lllc}
\hline & Range of Determination & \multicolumn{2}{l}{ Coefficient of Variation (\%) } \\
\cline { 2 - 4 } & & Range & Mean \\
\hline Leucocytes & $3 \cdot 56-20.50 \times 10^{3} / \mathrm{c} \mathrm{mm}$ & $1 \cdot 21-3.24$ & $2 \cdot 18$ \\
Haemoglobin & $5 \cdot 74-18.70 \mathrm{~g} / 100 \mathrm{ml}$ & $0 \cdot 95-1 \cdot 72$ & 1.20 \\
Erythrocytes & $1 \cdot 89-6.29 \times 10^{\circ} / \mathrm{c} \mathrm{mm}$ & $1 \cdot 77-2.06$ & $1 \cdot 88$ \\
\hline
\end{tabular}

Table I Precision of the Fisher Hem-Alyzer

\section{Accuracy}

To determine the accuracy 100 blood samples were divided into two aliquots and submitted t⿳⺈ analysis on the Hem-Alyzer and by an acceptable standard method. The standard methods used. were as follows: a Coulter model A cell count was used for white cell counts by the method $\mathbb{f}$ Richar and Breakell (1959) and for red cell couns: by the method of Brecher, Schneiderman, ang Williams (1956). The haemoglobin content was determined as cyanmethaemoglobin at $540 \mathrm{ng}$ in a Linson Junior colorimeter which had been calibrated with a cyanmethaemoglobin referenee standard, marketed by British Drug Houses Limited, and which conforms to the ICSP International Reference Standard. Each pair results was used for calculation of the statisticid data shown in Table II.

As is shown in Table II there is no significant $(P<0.05)$ average difference between the results of the two methods for white cefl counting $(t=1 \cdot 36$, degrees of freedom $=9 \vec{q}$ $0.2>P>0.1)$ and for haemoglobin conceg tration $(t=0.63$, degrees of freedom $=99$, $0.6>P>0.5)$. In order to test that the resu偶 from each pair of determinations were strongly associated, in a positive sense, the correlation coefficient (r) and regression equations were calculated. For white cell counting we found:

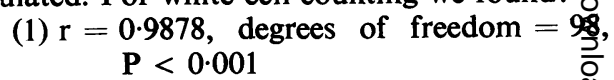

and (2) $y=0.9103 x+0.654$ (standard de\&ation from regression $S y \cdot x=0.59 \mathbb{B}$.

For haemoglobin concentration we found:

(1) $\mathrm{r}=0.9961$, degrees of freedom $=$ 悹, $\mathbf{P}<0.001$

and (2) $y=0.9717 x+0.408$ (standard dept ation from regression $S y \cdot x=0 \cdot 20$ )

The results of the comparison of the two independent red cell counting methods show significant value for ' $t$ ' $(t=4 \cdot 39$, degrees 'ôf freedom $=99, P<0.001)$. However, there was a very small difference between the means of the two methods, and there is strong positive corrrelation. For red cell counting we found:

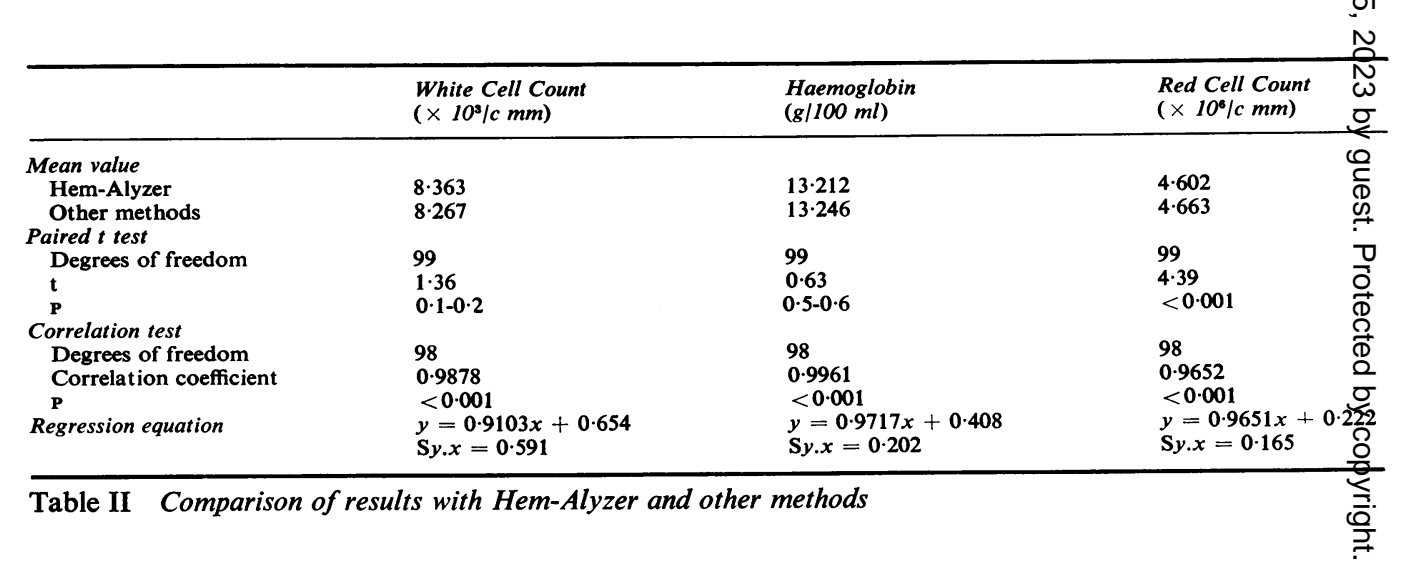


(1) $r=0.9652$, degrees of freedom $=98$, $\mathbf{P}<0.001$

and (2) $y=0.9651 x+0.222$ (standard deviation from regression $S y \cdot x=0 \cdot 165$ ).

\section{Mechanical and Electronic Reliability}

The Fisher Hem-Alyzer is of pleasing design: indeed it won an award in America in 1968 as a technical product of merit and significance. At the same time the instrument is soundly engineered and constructed of good quality materials to a high standard. As a consequence it performed reliably in routine daily use.

Provided the flow lines were regularly washed with detergent solution after each period of use, mechanical blockage was eliminated during the three-month period of study.

The electronic components of the main instrument appeared to be stable and the only electronic fault occurred in the accessory automatic printer, which intermittently failed to record one of the digits.

\section{Maintenance and Servicing}

If recalibration is necessary after replacement of

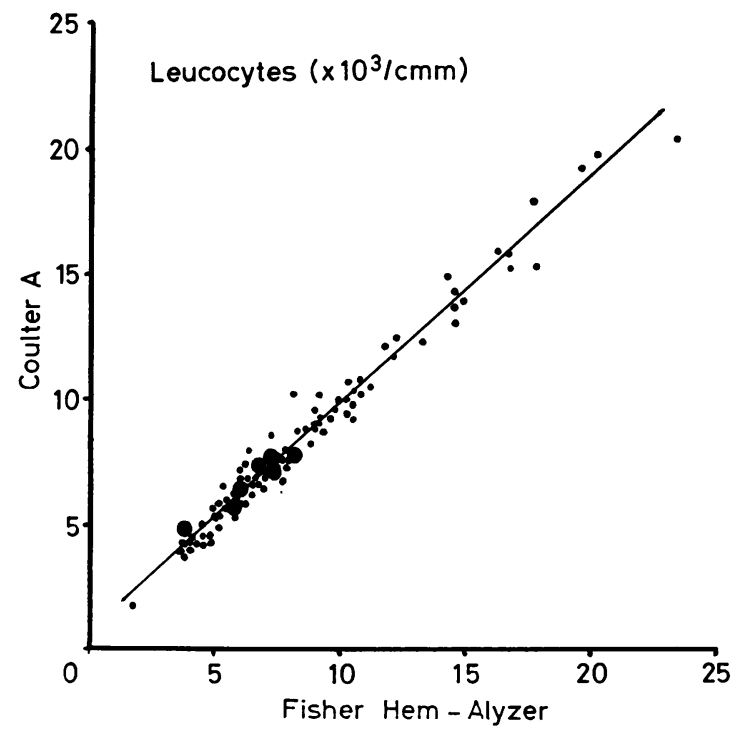

Fig. 1 Comparison of duplicate white cell counts $=$ single observation; $0=$ more than one coinciding observation). mechanical components then the new calibration $\stackrel{\complement}{\frac{C}{\bar{T}}}$ procedure should be effective, although we have $\overline{\bar{J}}$ had no opportunity to confirm this.

The routine maintenance requirements are $\stackrel{0}{5}$ easily achieved and involve the cleaning of the flow lines and the replacement of small items, $\overrightarrow{\bar{B}}$ such as light bulbs. The provision of a 'Trouble Shooter's Manual' has been most helpful in assisting laboratory technicians to detect and $\frac{\bar{\omega}}{2}$ correct faults in the equipment.

\section{Rate of Throughput}

A warming-up period of 20 minutes is required for the instrument to reach electronic stability. ? Several sample cups filled with saline, followed $\omega$ by at least five blood samples of known haemo- $\overrightarrow{-}$ globin concentration, are placed on the sample 8 turntable, which is then set in motion.

The rate of analysis of the instrument is $32-$ samples per hour. However, the number of test T samples which are routinely examined will be $\frac{\mathbb{O}}{2}$ fractionally less than this because of the introduction of a control sample in place of every twentieth test sample.

At the end of a day's run some detergent, $\supset$ followed by saline, is passed through the instrument and the cuvettes are then covered to protect them from dust.

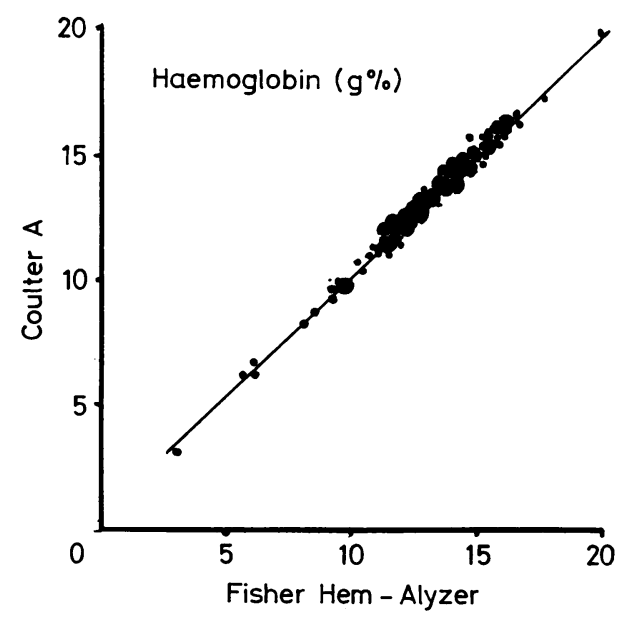

Fig. 2 Comparison of duplicate haemoglobin determinations $(\mathrm{O}=$ single observation; $\mathrm{O}=$ more than one coinciding observation). 


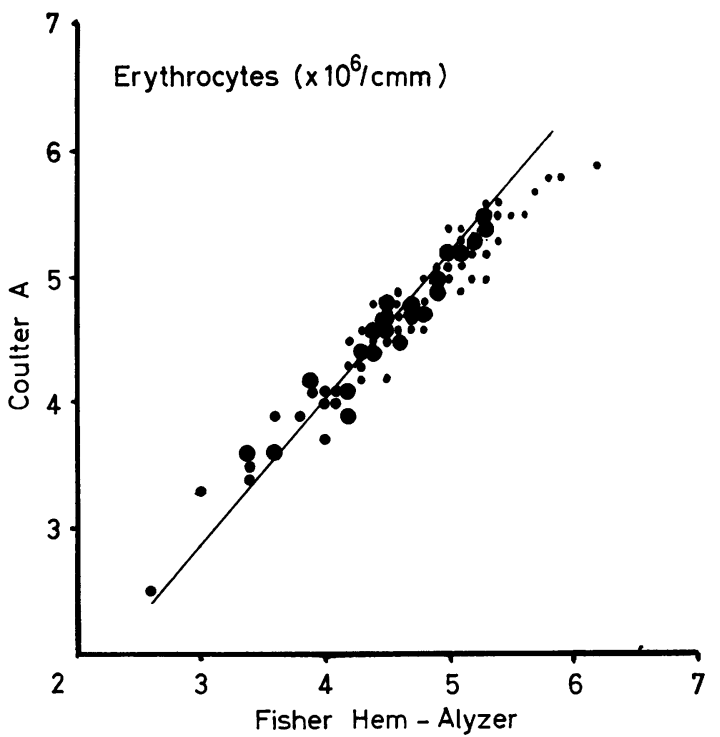

Fig. 3 Comparison of duplicate red cell counts $(\bullet=$ single observation; $\mathbf{O}=$ more than one coinciding observation).

\section{Data Handling}

While the printout of digitized results eliminates some of the problems involved in data handling, the necessity to transfer the results on to a standard hospital document from the original paper tape list is still required. The automatic production of record-compatible results would eliminate the possibility of transcription error introduced by this manual manoeuvre. It should be pointed out, however, that the equipment is provided with a computer interfaced circuit and plug, making it possible to relay the results directly to a more sophisticated data processing system.

\section{Running Costs}

The Fisher Hem-Alyzer uses only two reagent solutions, particle-free saline and Hemolyte. Sample cups and printout paper are also reqiured and the combined cost of these expendable items is currently $£ 112 \mathrm{~s} 4 \mathrm{~d}$ per hundred specimens. The total running costs are presented in TableIII, which include the expendables, the staff component, and a nominal servicing charge. Amortization over a five-year period, while not necessarily related to the life of the instrument, was chosen for comparative purposes, as it was

\begin{tabular}{|c|c|}
\hline Item & Total (£ \\
\hline \multirow{2}{*}{$\begin{array}{l}\text { Staff } \\
\text { Technician, part-time } \\
\text { Materials }\end{array}$} & 750 \\
\hline & \\
\hline $\begin{array}{ll}\text { Reagents } & 325 \\
\text { Plastic sample cups } & 600\end{array}$ & 으 \\
\hline & 9 萤 \\
\hline \multirow{3}{*}{$\begin{array}{l}\text { Electricity } \\
\text { Maintenance and servicing } \\
\text { Amortization Over five years }\end{array}$} & 30 \\
\hline & 2,0 贯 \\
\hline & $£ 3,8$ 先 \\
\hline
\end{tabular}

Table III Annual running cost of Fisher Hem-Alyz $\vec{B}$ based on a workload of 60,000 specimens/year 'Nominal.

originally used in the cost analysis of the other items of multichannel equipment (Nelson, 196\% The costing of the Hem-Alyzer is based on workload of 60,000 specimens per year and worked out at 1.3 shillings per specimen, which. 15 a little cheaper than the cost per specim obtained on both the SMA-7 and the Coulter model S, which we calculated to be approximatefy 1.6 shillings per specimen. However, both the SMA-4 and Coulter model $S$ produce seven parameters, whereas the Hem-Alyzer produces only three.

This study was undertaken at the request of tre Laboratory Equipment and Methods Advisory Growp of the Department of Health and Social Securie, London.

We are grateful to Messrs Fisons Scienti) Apparatus Limited for making the Hem-Alyzer available for evaluation.

\section{References}

Brecher, G., Schneiderman, M., and Williams, G. Z. (1956). Evaluation of electronic red blood cell counter. Amer त्तें. clin. Path., 26, 1439-1449.

Carville, J. M., and Lee, D. (1969) Red cell suspension asón working standard. J. clin. Path., 22, 738.

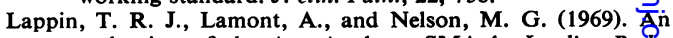
evaluation of the AutoAnalyzer SMA-4. J. clin. PaD., 22, 11-18.

Nelson, M. G. (1969). Multichannel continuous flow analysis ${ }^{n}$ the SMA-4/-7A. J. clin. Path., 22, suppl. (Coll. Path.) 230-25.

Richar, W. J., and Breakell, E. S. (1959). Evaluation of an tronic particle counter for the counting of white blood cells. Amer. J. clin. Path., 31, 384-393. 